significant part which gelatine and glue have played in the history of colloid science, even to the extent of contributing the name from $\left.x^{6}\right\rangle \cdot \lambda \alpha$, glue. The peak period for the academic study of gelatine as the typical hydrophilic colloid was during 1920-30, following the classical work in Great Britain of Procter and Wilson, and in the United States of Jacques Loeb. Interest has since been transferred to other proteins. There is a possibility that an intensive study of gelatin might throw new light on structural proteins, and also on their relation to globular proteins and hence on the entire field of protein chemistry and physiology. Prof. Roughton also emphasized the need for industry and the universities to take an interest in each other's work, and the important function a research association can discharge in acting as a link.

Mr. G. W. Odey, president of the Association, in replying to the toast, emphasized the dual need to be prepared to meet all demands on the industry in time of war, and to make a contribution in time of peace to the problem of balance of payments. He stressed the way in which the interplay of minds and of ideas has furthered scientific progress, although it is often difficult to trace the antecedents of any one discovery. The wide variety of industries which are users of gelatine and glue gives the industry an importance out of proportion to its size, and the research done will be of assistance over a wide field. He announced a donation of $£ 1,0 \mathrm{CO}$ to the Association from British Glues and Chemicals, Ltd., to mark the opening of the laboratories, and expressed his confidence in the future development of the work.

Mr. S. G. Hudson, chairman of the Association, directed attention to the very great assistance rendered to the Association by the Department of Scientific and Industrial Research and its stations, by other research associations, and by many other research workers.

The laboratories were inspected by those present and on the following day, November 30 , were opened to visitors. The exhibits were designed to illustrate the scientific work carried out since the first staff were recruited just over two years ago. In addition, there was a display of the production methods of the industry, divided into the two parts, gelatine manufacture and bone glue manufacture, which included photographs of all stages of the processes, as well as examples of the materials at these stages.

The use of mixed bed ion-exchange columns for removing ionizable impurities from gelatine or glue was shown, together with an application of the method to the determination of isoelectric point. The significance of isoelectric opalescence of gelatin gels was also shown. A modified paper-chromatographic technique for amino-acids was illustrated with actual chromatograms. Analytical methods included colorimetric procedures for copper, iron and phosphate in gelatine and phosphate in bone meal. The application of Sanger's end-group technique to gelatin was demonstrated, the separation of the coloured aminoacid derivatives being clearly visible on the 'Celite' chromatographic columns. The isolation and properties of a mucopolysaccharide from compact bone tissue showed the importance of the non-collagenous constituents. Methods were demonstrated for determination of colour and clarity in gelatin, and for studies of the viscosity of dilute solutions. The marked reduction in bacterial content of deionized gelatin, immediately after deionization, was illustrated by figures of the bacterial counts. Interest in the technical laboratory was primarily directed to the newly built apparatus for freeze-drying gelatin or glue. Many other items of equipment were on show, establishing the very well equipped condition of the Laboratories.

On November 28, 1951, the Research Panel of the Association met at Beales Restaurant. The meeting was well attended by the staff of member firms, of government departments, of research associations, etc. The first paper was entitled "The Conversion of Collagen to Gelatin and their Molecular Structures" and was given by Dr. W. M. Ames, of J. and G. Cox, Ltd. Dr. Ames described the work he has carried out over a period of years, on the scientific basis of the manufacture of gelatin from hide and sinew. This work showed the primary importance of the pretreatment of the raw material, by alkali or acid, in determining not only the ease of production of gelatin, but also in deciding the properties which the product would have. Dr. Ames also put forward two theories of the structure of collagen and the mode of its conversion to gelatin. The latter part of Dr. Ames's lecture gave rise to a lively discussion, together with some criticism, in the light of the work of the Association and of Dr. J. H. Bowes, of the British Leather Manufacturers' Research Association.

'The second paper was given by Dr. G. Stainsby, of the Association's staff, on "The Viscosity of Dilute Gelatin Solutions", which dealt with the work Dr. Stainsby has carried out since joining the Association. This aroused interest particularly from furms using gelatine.

This meeting of the research panel was followed by the annual general meeting of the Association. The chairman, Mr. Hudson, in commenting on the annual report, stressed the importance of expanding the membership, to enable full use to be made of the facilities of the Association. The director of research, Mr. A. G. Ward, described the research which was being carried out, and showed the relation between the various items of the programme and the main scientific problems of the industry. Mr. B. G. McLellan, of the Department of Scientific and Industrial Research, commended the ready interchange of views which took place at the meetings of the Assuciation, and also expressed appreciation of the way in which Prof. Roughton and himself had been brought into the various activities. Mr. G. W. Odey was re-elected president of the Association, and the only change in the composition of the Council was the addition of Mr. C. F. C. Simeons.

\section{INTERLINGUAL AND SCIENTIFIC DICTIONARIES}

\begin{abstract}
SECOND revised edition of the report on interlingual scientific and technical dictionaries circulated in July 1949 has now been issued*. This reflects the development of ideas through discussion of the original report, and the revised edition is published in the hope of eliciting comment from a wider circle which may further help in formulating Unesco's policy in this matter.

Ideas on the production and distribution of special dictionaries are still fluid; but Dr. Holmstrom envisages three basic principles as important. The * Report on Interlingmal Scientific and Techniral Dictionaries. By Unesco; London : H.M. Stationery Office, 1951.) 18. $6 d$. net.
\end{abstract}


terminology appertaining to each subject should be a responsibility of the international scientific or technicul organization cultivating that subject. The first step should be to distinguish and to register under serial numbers the actual concepts, regardless of what words may rightly or wrongly be associated with those concepts according to the usages of different languages. In each language certain expressions should be standardized in the sense of being officially recommended for denoting particular concepts, as distinguished by sketches if concrete or by verbal definitions if abstract. Dr. Holmstrom visualizes the international organization desiring a dictionary for its special subject as first adopting a list of the requisite terms, together with illustrative sketches or definitions or descriptive verbal contexts in any suitable basic language and numbering them for reference. The agreed and numbered definitions, but not the terms themselves, would then be translated into each of the other languages desired and would be sent to authoritative organizations in countries using those languages. These organizations would respond with lists of the terms in their respective languages which they recommended should be associated with the numbered definitions or illustrations, and the international organization would then publish a dictionary quoting the terms thus collected, with or without the definitions or illustretions.

Dr. Holmstrom also directs attention to the advantage gained if no term intended for inclusion in a dictionary need be copied more than once from the time it is first suggested to the time it appears in the published work.

The bibliography which accompanied the original report has now been published separately*. It now includes 1,044 references grouped under 224 subject heads in accordance with the Universal Decimal Classification numbers, and taken from forty-five languages. The bibliography is bilingual, in French and English, and is provided with a language index as well as with the customary author and subject indexes. Fifty further dictionaries are listed in a supplement.

* Bibliography of Interlingual Scientific and Technical Dictionaries. By Dr. J. F. Holmstrom. Serond edition, with corrections and supplement. Pp. 232. (Paris: Unesco; London: H.M. Stationery Office,

\section{CONTEMPORARY PSYCHOLOGY IN THE SOVIET UNION}

PAPER by Ivan D. London, of Harvard
University, on "Contemporary Psychology in
the Soviet Union"*, discusses the present-day general
policy towards the subject which the Soviet Govern-
ment is forcing its psychologists to adopt ; the
paper cites 104 references with full titles and dates
of publication. It appears that the genetics con-
troversy of 1948 in the U.S.S.R. was followed in
1950 by a similar controversy ; but this time concerned
with physiology and the allied subject of psychology,
the alleged focal point being the work of Pavlov.
Apparently, writers in the U.S.S.R. concerned with
these two sciences have not shown sufficiently strong
allegiance to the "materialistic foundations" of
Pavlov. Although in the prefaces to their books
Soviet physiologists and psychologists referred to the
"materialistic foundations bequeathed to them by
Pavlov", they proceeded to develop their sciences without much reference to his theories. Trouble resulted, and Rubinshtein, the only Soviet psychologist to date to develop a respectable general psychology on paper, had to confess to a "grievous sin" in that in his book of 685 pages, "Bases of General Psychology", he takes up questions connected with Pavlovian theory on only six pages. The American and English physiologists, Liddell and Sherrington, have been accused of showing evidence of "a bourgeois plot", and Sherrington and Pavlov personify respectively the forces of evil and good. Pavlov, who died in 1936, is represented as always an upholder of present-day Soviet theses and as being a posthumous supporter of Lysenko.

The consequence is that psychology in the U.S.S.R. has become an uninspiring discipline, more a matter of programme than of accomplishment, and even the work of out-and-out Pavlovians is little more than an unimaginative rehashing of past experiments. Some interesting experiments of Anokhim and his co-workers led to an attempt to escape from the limitations of the standard Pavlov technique, and he devised a general method which he calls the "method of active choice". In his view the role of reflexes as such is subordinated to that of "large-scale functional systems" (1949). He has, however, been condemned for his deviationism from the Pavlov theory. •

In the field of sensation and perception, particularly that concerned with "sensory interaction", there is considerable Soviet work of apparent competence. Any non-visual stimulation that increases retinal sensitivity to green light has been found to decrease it to red light. Substances which heighten sympathetic excitability, such as adrenalin and ephedrine, increase retinal sensitivity to light in the green-blue region of the spectrum. Substances which heighten parasympathetic excitability, such as pilocarpine, increase sensitivity to light in the orange-red region (1950). Other interesting investigations are concerned with brain-function in its normal, pathological and restorative aspects.

Since 1936, educational psychology in the U.S.S.R. has been relegated in the main to the service of pedagogy. On the basis of an observational study of three gifted children, a psychologist notes that talent is accompanied by a remarkable inclination to work. The conclusion is drawn that "workers have an enormous advantage over the parasitic classes, and that in spite of the test-data of foreign scientists there is greater talent in the working classes"

There are a number of Soviet psychological journals ; but the quality of the papers is extremely uneven, and the intrusion of political propaganda is a common feature. When in 1947 a second edition of Rubinshtein's "Bases of General Psychology" was published, although in 1942 it had been awarded the Stalin Prize, he was unreasonably attacked because it was said that he had neglected the psychology of the "new Soviet man", and had not correctly resolved the psycho-physical problem. The political and ideological strait-jacketing of psychology in the U.S.S.R. has been both restrictive and deleterious to its development; in contrast to the treatment of psychology, some branches of mathematics and of the physical sciences rival comparable work in other countries.

* Contemporary Psychology in the Soviet Union. By Ivan D. Massachusetts.) From Science, 114, 227-233 (1951). 